\title{
The clinical importance of color Doppler ultrasonography in puncture related complications of hemodialysis vascular access
}

\author{
Mohammed H. Hassan ${ }^{1 *}$ (D), Ghada M. Abdelrazek² and Abdelkader A. Hashim³
}

\begin{abstract}
Background: The long-term survival of patients on hemodialysis (HD) is dependent on adequate HD which depends on quality and degree of functionality of vascular access. The aim of our study is to detect the role of color Doppler ultrasonography in evaluation of arteriovenous fistula (AVF).

Materials and methods: Between January 2017 and October 2017, 60 patients had complicated AVF at Qena General Hospital \& Qena University Hospital as primary and tertiary centers respectively with the same age group between 18 and 50 years old, had no diabetes mellitus were evaluated using color duplex-Doppler ultrasound (CDUS) after AVF maturation for detection of complications and comparison between primary and tertiary centers of its incidence.

Results: The overall results revealed that 11 patients from 30 patients that had been referred to tertiary centers have complicated AVF (36.7\%), and 19 patients had no shunt complication (63.3\%). Twenty-two patients from 30 patients that had been referred to primary HD centers had complicated shunts. Thrombosis at tertiary centers represents $13.3 \%$, stenosis $3.3 \%$ (1 patient), aneurysmal formation had $6.6 \%$ for (2 patients), hematoma $6.6 \%(2$ patients), infection 3.3\% (1 patient), venous hypertension 3.3\% (1 patient), thrombosis and hematoma at primary centers 16.6\% (5 patients for each), aneurysmal formation and infection 13.3\% for each, and stenosis 10\%.

Conclusions: CDUS is a readily-available, non-invasive, risk-free, bed-side technique that allows precise anatomic knowledge, qualitative, and quantitative data of the upper limb vascular system which greatly help in preoperative planning of AVF creation, assessment of prime time for puncture (maturation), early detection of complications, and choice of appropriate therapeutic procedure for their treatment.
\end{abstract}

Keywords: Color Doppler ultrasound duplex ultrasound, Arteriovenous fistula, End stage renal failure, Hemodialysis

\section{Background}

Hemodialysis has an important role in long-term survival of patients with end-stage-renal disease (ESRD). To maintain them on long-term dialysis, vascular access procedures are required [1]. A well-functioning vascular access has a good blood flow, excellent patency, and allows easy and repetitive cannulation with two needles.

\footnotetext{
* Correspondence: Mohammedhosnyhassaan@yahoo.com; mohammedhosnyhassaan@med.svu.edu.eg

'Department of Medical Biochemistry, Faculty of Medicine, South Valley University, Qena 83523, Egypt

Full list of author information is available at the end of the article
}

The arteriovenous fistula (AVF) provides the best access for longevity and lowest morbidity and mortality; however, arteriovenous grafts remain clinically important in elderly patients and whom AVFs are not feasible [2]. After surgical creation, the vein distended to become a successful arteriovenous fistula (AV). Fistula undergoes a remodeling process that is referred to as maturation. Although somewhat variable, these changes occur relatively rapidly, resulting in a fistula that can be repetitively used and which can provide adequate dialysis treatments [3]. Ideal time needed for arteriovenous fistula (AVF) maturation is still controversial. Early 
detection of access dysfunction, complication allows for subsequent interventions that help to reduce the rate of access failure [4]. Failure of the A-V fistula can be early or late. Early failure of the vascular access for hemodialysis is accounted for the period between creation and the beginning of the work of the fistula, or within the first 3 months of its use. On the other hand, late failure of the A-V fistula is considered if it happens after 3 months of its use for hemodialysis [5]. US can help also to identify other complications associated with fistulas including abscess, aneurysm, steal syndrome, and hematoma scan also be evaluated by color Doppler examination [6]. Color Doppler ultrasonography enables preoperative vascular mapping for AVF creation, assessment of prime time for puncture, early detection of complications, and choice of appropriate therapeutic procedures for correction [7]. The long-term survival and quality of life of patients with ESRD on hemodialysis is dependent on the adequacy of dialysis via an appropriately placed vascular access [8]. Duplex ultrasound is rapidly emerging as an essential investigation, and its widespread introduction in the future will have major resource implications [9].

\section{Methods}

The current study is observational prospective randomized controlled trial study of 60 patients of end stage renal disease (ESRD) an observational prospective study conducted at Qena University Hospital during the study period from January 2017 to June 2018.

\section{Patients}

The study included 60 patients with ESRD for AVF evaluation, aged from 18 to 50 years.

\section{Inclusion criteria}

- Clinically stable

- Patients on hemodialysis with late complication of AVF

- Age group from 18 to 50 years old

- All AVFs had been done at Qena University Hospital with the same preoperative assessment and operative technique

- Those with early complications

\section{Exclusion criteria}

- Diabetic patients

- Patients with peripheral vascular disease

\section{Equipment and supplies}

- Grey scale and color Doppler GE LOGIC P7 ultrasound machine with high frequency transducers
(8-10 MHz). Standard supplies for ultrasonic exam: acoustic coupling gel, gloves, and skin wipes

\section{Methodology}

The preoperative criteria to be met for vascular access are summarized as follows:

- Arteries $2.0 \mathrm{~mm}$ or larger

- Veins, $2.5 \mathrm{~mm}$, or larger for AVF

- Depth of the vein from the skin surface $<5 \mathrm{~mm}$

- Superficial vein continuing to the deep venous system

- Absence of central venous stenosis

- Absence of evidence of arterial stenosis segments

- Patients who undergo upper limb AVFs will be examined with US Doppler after 3 months, 6 months, and 12 month for detection of late complications.

\section{Indications for CDUS examination [10]}

A) Clinical symptoms and signs of insufficiency of AV access:

- Poor arterial flow with access collapse

- Thrill loss

- Ischemia of the distal limb

- -Impaired matured fistula

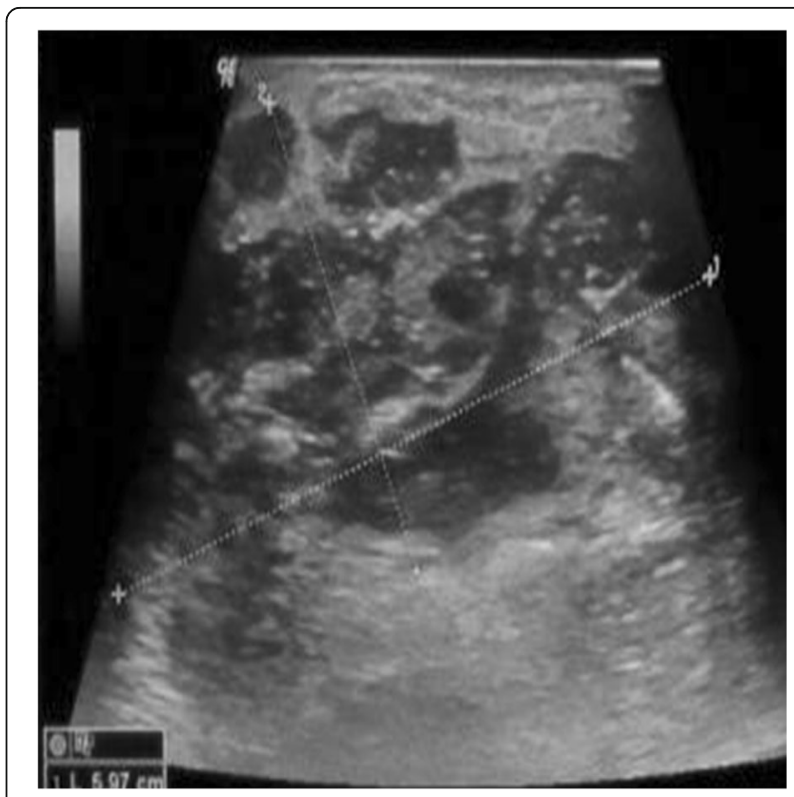

Fig. 1 Case with B-B fistula on gray scale image shows an infected hematomas forming subcutaneous abscesses 
Table 1 Frequency of AVF complications among the included patients

\begin{tabular}{|c|c|c|c|c|}
\hline \multirow[t]{3}{*}{ AVF complications } & \multicolumn{4}{|l|}{$\begin{array}{l}\text { Patients } \\
(n=60)\end{array}$} \\
\hline & \multicolumn{2}{|c|}{$\begin{array}{l}\text { Patients referred from primary center } \\
(N=30)\end{array}$} & \multicolumn{2}{|c|}{$\begin{array}{l}\text { Patients referred from tertiary center } \\
(N=30)\end{array}$} \\
\hline & Number & $\%$ & Number & $\%$ \\
\hline Hematoma & 5 & 16.6 & 2 & 6.6 \\
\hline Infection & 4 & 13.3 & 1 & 3.3 \\
\hline Thrombosis & 5 & 16.6 & 4 & 13.3 \\
\hline Stenosis & 3 & 10 & 1 & 3.3 \\
\hline Pseudo-aneurysm & 3 & 10 & 1 & 3.3 \\
\hline Venous aneurysm & 1 & 3.3 & 1 & 3.3 \\
\hline Venous hypertension & 1 & 3.3 & 1 & 3.3 \\
\hline Total & 22 & 73.3 & 11 & 36.7 \\
\hline
\end{tabular}

- Clinical suspicion of infection

- Perigraft aneurysm or pseudo-aneurysm or mass

B) Malfunction of the fistula as evidenced by:

- Cannulation difficulty

- Thrombus aspiration

- Increased venous pressure more than $200 \mathrm{mmHg}$ on a $300 \mathrm{cc} / \mathrm{min}$ pump

- Increased recirculation time $\geq 15 \%$

- Decreased reduction rate of urea ‘ $60 \%$

Post-procedure ultrasound technique using step-by-step protocol for vascular access assessments [11]

The following will be assessed:

- The diameter and compressibility of the draining vein is studied routinely in the caudal, mid-, and cranial portions of the forearm, and similarly in the upper arm.

- The depth of the anterior wall of the AVF from the skin surface is also measured.
- Blood flow is measured in the AVF in $\mathrm{ml} / \mathrm{min}$ using the volume flow measurement function of the duplex instrument at a site far enough from the anastomosis. Three measurements will be performed, and the final value used in the study will be the arithmetic mean.

\section{Assessment of AVF complications: sites of examination included}

- The afferent artery

- Site of anastomosis

- The draining veins as far as the subclavian vein

- The arterial tree distal to the AVF in cases suffering from steal syndrome

\section{Doppler parameters and measurements}

Each of the following parameters was measured at the site of AV anastomosis, at the afferent artery and finally at the draining vein.

- $\mathrm{PSVcm} / \mathrm{sec}$

- $\mathrm{EDV} \mathrm{cm} / \mathrm{sec}$

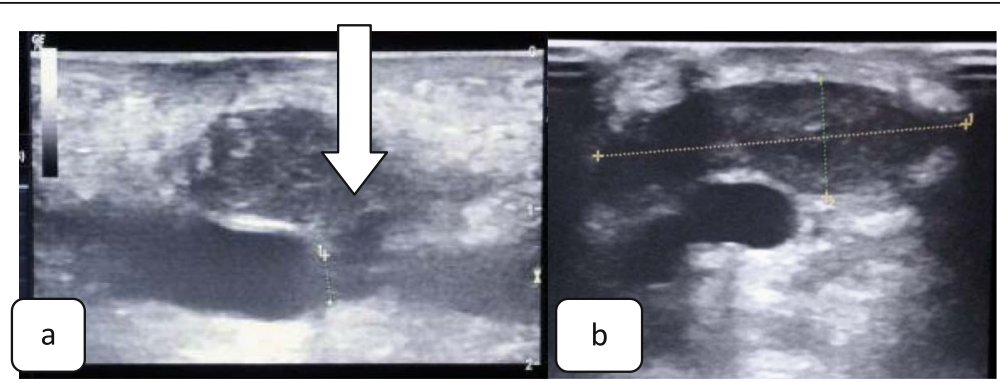

Fig. 2 Gray scale images show a hematoma at the puncture site, anterior to the venous side of AVF, a sagittal view shows site of puncture (arrowed) and vein lumen reduction by the mass effect of hematoma, $\mathbf{b}$ shows the site\& dimensions of the hematoma 


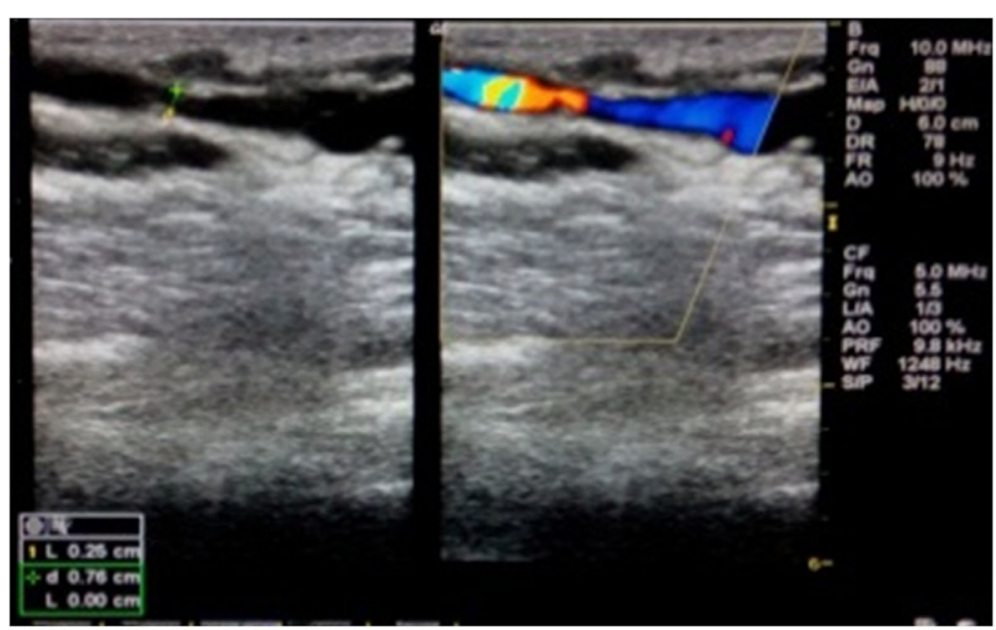

Fig. 3 Segmental narrowing of the cephalic vein with aliasing of the post-stenotic flow

- $\mathrm{RI}$

- Volume of blood flow ( $\mathrm{ml} / \mathrm{min})$

- The distal arterial tree was examined in cases suffering from steal syndrome.

\section{Results}

In this study, we started with 60 patients with ESRD candidate for hemodialysis AVF whom have no history of diabetes mellitus, and various types of well-functioning AVFs had been done for them at Vascular Surgery Department-South Valley University Hospitals . 24 patients (40\%) had B-C, (18 patients,30\%) had B-B fistula (Fig. 1) and (18 patients, 30\%) had R-C fistula. Fifty percent of patient populations had been referred to the Hemodialysis Unit of SVU Hospitals as a tertiary hemodialysis center where good nursing, and the other $50 \%$ of patient population had been referred to Qena General Hospital as a primary hemodialysis center.

Maturation of an AV fistula typically occurs within the first 4 weeks after creation. The mean age of maturation in our study of the fistulae encountered was $4 \pm 0.379$ weeks.
We found that the mean blood flow rate in adequately functioning AVFs was $816.21 \pm 152 \mathrm{ml} / \mathrm{min}$. after creation of fistula.

Our study demonstrates that $22(73.3 \%)$ out of 30 patients who referred from the primary center developed AVF complications as follow: hematoma [5 cases (16.6\%)] with same frequency regarding thrombosis, infection $[4$ cases $(13.3 \%)]$, stenosis and peudoaneurysm with the same frequency [3 cases (10\%)], venous aneurysm and venous hypertension also having the same frequency [ 1 case (3.3\%)]. While, 11 patients from 30 patients had been referred to tertiary center who have complicated AVF (36.7\%), and 19 patients had no shunt complication (63.3\%). Thrombosis $13.3 \%$ (4 patients), hematoma $6.6 \%$ (2 patients), aneurysmal formation had $6.6 \%$ for (2 patients) one patient on the venous side and the other on the arterial side, stenosis 3.3\% (1 patient), infection 3.3\% (1 patient), and venous hypertension $3.3 \%$ (1 patient) (Table 1 and Figs. 2, 3, 4, 5, 6, 7).

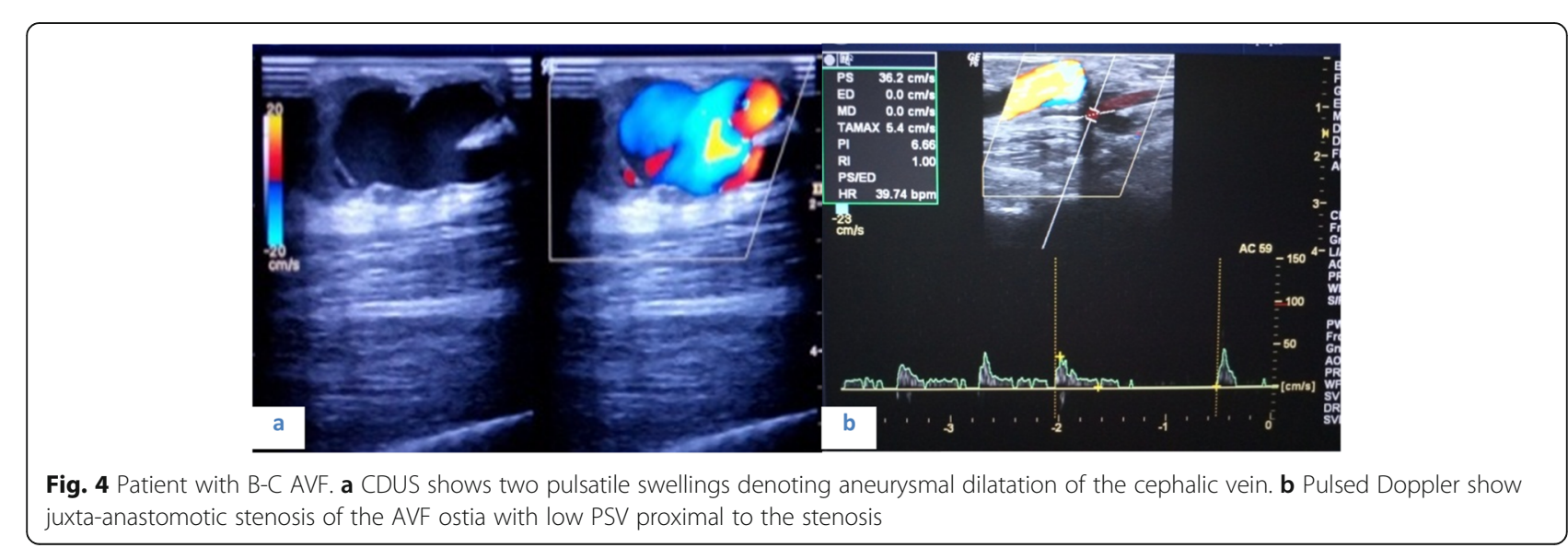




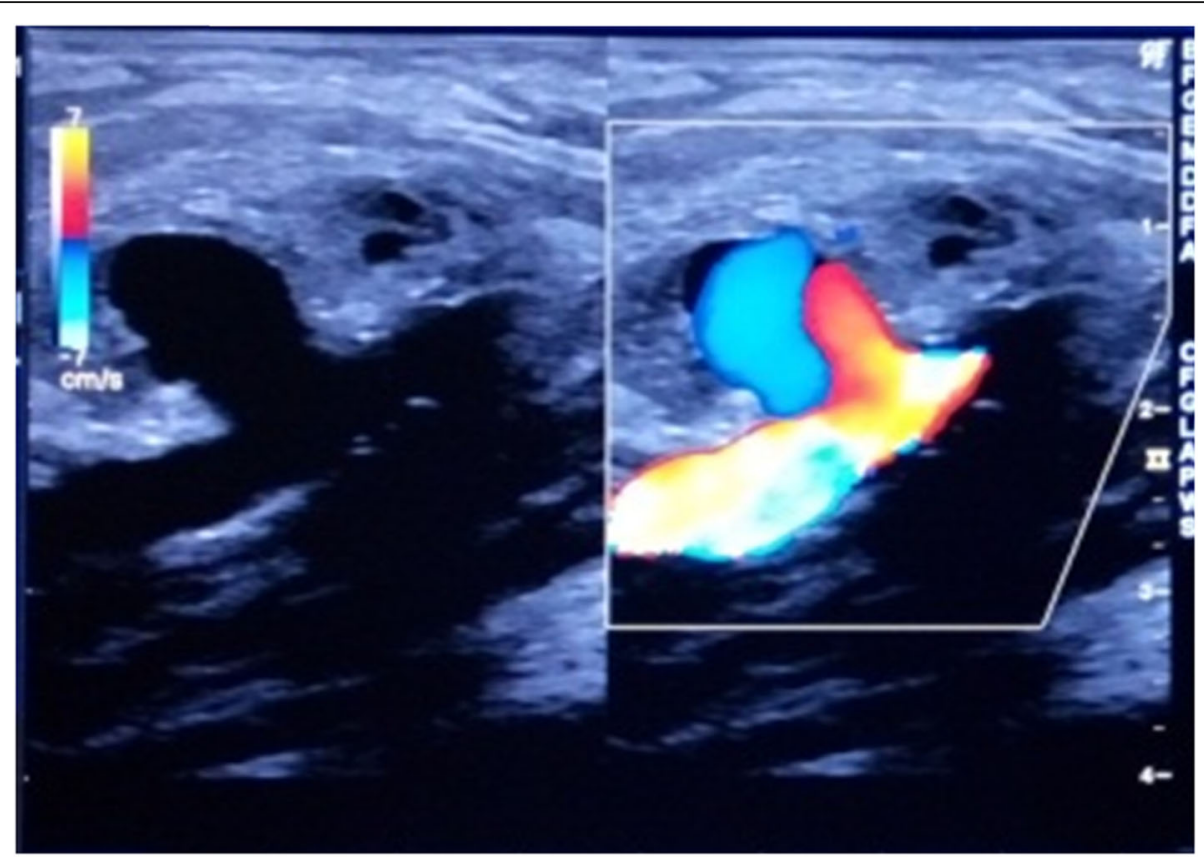

Fig. 5 CDUS shows pulsatile swelling at site of puncture of AVF with swirling "yin-yang" pattern of blood flow typically seen in pseudoaneurysms

\section{Discussion}

Vascular access problems remain the vulnerable point of modern HD [12]. For evaluation of access dysfunction, the initial, most practical, and cost-effective method is physical examination [13]. US confirm the results of physical examination such as inflow stenosis and outflow stenosis. Moreover, it provides important information about the functional severity like brachial artery flow rates $[14,15]$. By combining the findings of US and physical examination, the treatment methods can be determined, such as angioplasty, revision surgery, or conservative management [16]. Moreover, Doppler US shortens angioplasty time, as it gives information on the

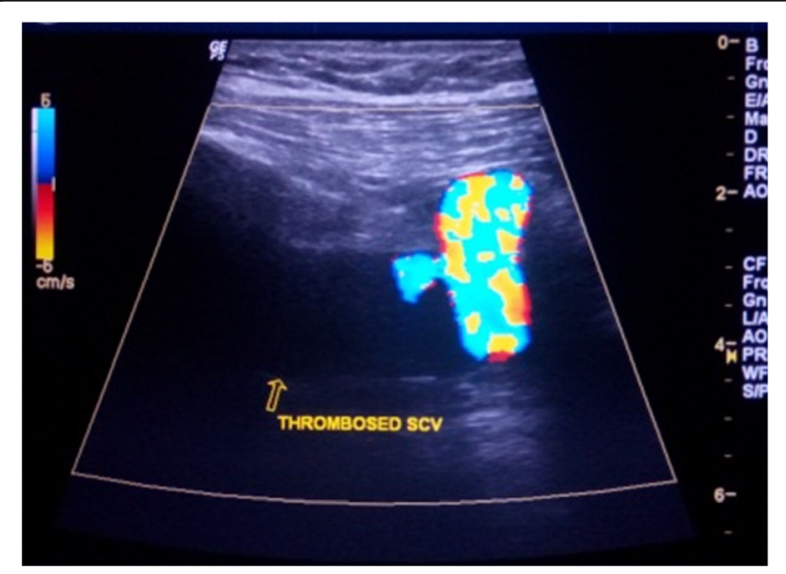

Fig. 6 CDUS shows central venous thrombosis and venous hypertension stenosis site [17]. Thus, by the use of US, more clinical needs are satisfied [16].

The present study demonstrated that, during the first 11 months of newly created AVFs, a great percentage of patients encounter cannulation related complications were significantly higher in primary than tertiary centers of hemodialysis.

In this study, we evaluated the clinical utility of CDUS for early detection of complications in AV dialysis access. We found that the number of female patients exceeded that of males, with 36 female patients and 24 male patients, representing 60 and $40 \%$ of all patients, respectively. This correlates with the findings of the previous studies who found that fistulas are less likely to be usable for dialysis in female than in male patients [18].

Among our study population, the most common shunt complication associated with HD was access to thrombosis $(n=5,16.6 \%$ in primary centers and $n=4,13.3 \%$ in tertiary centers). Thrombosis is usually located in the arteriovenous anastomosis of the AVF. In our study, thrombosis was detected at the venous side of the fistula in most cases; diagnosis of thrombosis was established by absence of flow using color or pulsed Doppler together with hypoechoic or echogenic thrombus filling the lumen.

Stenosis of HD vascular access is common and may lead to thrombosis and the loss of the access. Thus, detection of stenosis in AVF before thrombosis could offer a strategy to improve AVF survival by early intervention [19]. Stenosis in AVF develops more frequently in juxtaanastomotic location, up to $4 \mathrm{~cm}$ from the anastomosis [20]. Among 4 patients diagnosed with stenosis, one 


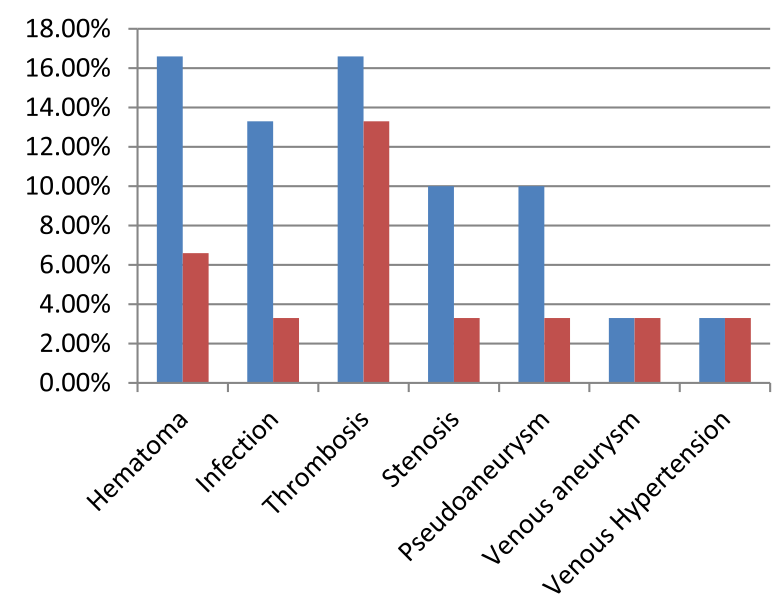

- Primary center

- Tertiary center

Fig. 7 Frequency of AVF complications among the included patients referred from primary and tertiary centers

cases had post-fistula stenosis, three cases had stenosis at the anastomotic site. This was in accordance with the finding of Tirinescu et al. [19], who performed a large observational study on 97 patients, and reported juxtaanastomotic localization of stenosis in most cases, in the forearm, and in the upper arm AVF equally.

Clinically pseudoaneurysms are diagnosed by the presence of a pulsatile mass with systolic murmur. However, CDUS is particularly suitable to determine the extent of the aneurysm and to demonstrate thrombotic material within the aneurysmatic sac [21]. Out of the examined cases in our study, 6 patients had pseudoaneurysm (12\%), 4 at the venous side of the AVF, 1 at the site of anastomosis, and 1 at the arterial side, which is relatively rare. Puncture of an AVF either as part of standard dialysis needling or from intervention can result in prolonged bleeding and pseudoaneurysm formation. However, the mechanism of formation of true aneurysms in AVFs is less clear. This is may be attributed to also to repeated needling with consequent development of multiple small fibrous scars in the vessel wall that expand with time and result in localized aneurysmal areas [22, 23].

Tenderness and erythema along the access can indicate infection. An untreated access infection may lead to bacteremia, sepsis, hemorrhage, and, if left untreated, possible death. In this study, 4 patients $13.3 \%$ in primary centers had an infected AVF, and only one patient had an infected AVF 3.3\% in tertiary centers, due to the use of complete antiseptic measures in tertiary centers.

Venous hypertension results from arterialization of the venous system proximal to an arteriovenous fistula with central venous occlusion [24]. Our study included 2 patients with venous hypertension (4\%) due to central venous stenosis.

The CDUS findings in this series were helpful to determine further therapeutic management in patients with AV dysfunction.
The limitation of this study is the relatively small number of patients with selection bias including only patients with suspected AV dysfunction on physical examination. A larger study including all patients for surveillance of AVF is recommended.

\section{Conclusions}

CDUS is a noninvasive diagnostic tool for early detection of complications of AVFs that allows monitoring of the AVF blood flow and detection of possible causes of vascular access malfunction. Owing to its low cost and availability, it should be used as the first-line imaging modality for dysfunctional AVF. Well-qualified nurses are very important in reduction of AVF complications, and tertiary centers should help primary centers in continuous education of nurses.

\section{Abbreviations}

AVF: Arteriovenous fistula; CDUS: Color Doppler ultrasonography; EDV: End diastolic velocity; ESRD: End stage renal disease; HD: Hemodialysis; PSV: Peak systolic velocity; RI: Resistive index; SVU: South Valley University

\section{Acknowledgements}

NA

\section{Authors' contributions}

GM and AA were responsible for study concept and design. AA was responsible for clinical evaluation of the cases. GM was responsible for imaging data. GM, AA, and $\mathrm{MHH}$ were responsible for data analysis and writing manuscript. All authors revised and approved the final version of the manuscript.

\section{Funding}

This study had no funding from any resource.

\section{Availability of data and materials}

The datasets used and/or analyzed during the current study are available from the corresponding author on reasonable request.

\section{Ethics approval and consent to participate}

The current study has been approved by the Ethics committee of the Faculty of Medicine, South Valley University, Qena, Egypt, and was done in accordance with Declaration of Helsinki. An informed written consent has been obtained from every included patient. 
Ethics committee's reference number: 12/2016.

\section{Consent for publication}

All patients included in this research gave written informed consent to publish the data contained within this study. If the patient was less than 16 years old, deceased, or unconscious when consent for publication was requested, written informed consent for the publication of this data was given by their parent or legal guardian.

\section{Competing interests}

The authors declared no potential conflicts of interest with respect to the research, authorship, and/or publication of this article.

\section{Author details}

'Department of Medical Biochemistry, Faculty of Medicine, South Valley University, Qena 83523, Egypt. 'Radiology Department, Faculty of Medicine, South Valley University, Qena, Egypt. ${ }^{3}$ Internal Medicine Department, Faculty of Medicine, Assiut University, Assiut, Egypt.

Received: 1 August 2019 Accepted: 27 November 2019

Published online: 16 December 2019

\section{References}

1. Asif A, Roy-Chaudhury P, Beathard GA (2017) Early AVF failure: a logical proposal for when and how to intervene. C J Am Soc Nephrol. 1(2):332-339

2. Centers for Medicare and Medicaid Services: Empire medical local coverage determination, August 2010, http://www.cms .hhs.gov/MCD/.

3. Cho S, Lee YJ, Kim SR (2017) Clinical experience with ultrasound guided angioplasty for vascular access. Kidney Res Clin Pract 36:79-85

4. Davidson I, Chan D, Dolmatch B, Hasan M, Nichols D, Saxen R (2008) Duplex ultrasound evaluation for dialysis access selection and maintenance: a practical guide. J Vascular Access. 9(1):1-9

5. Ethier J, Mendelssohn DC, Elder SJ et al (2008) Vascular access use and outcomes: an international perspective from the Dialysis Outcomes and Practice Patterns Study. Nephrology Dialysis Transplantation. 23:3219-3226

6. Ferring $M$, Henderson J, Wilmink A, Smith S (2008) Vascular ultrasound for the pre-operative evaluation prior toAVF formation for hemodialysis: review of the evidence. Nephrol Dial Transplant. 23(6):1809-1815

7. Gerald A, Beathard MD (2016) PhD, Maturation and evaluation of the newly created hemodialysisarteriovenous fistula. Sep 12

8. Guedes Marques M, Ibeas J, Botelho C, Maia P, Ponce P (2015) Doppler ultrasound: a powerful tool for vascular access surveillance. Semin Dial 28:206-210

9. Kumbar L, Karim J, Besarab A (2012) Surveillance and monitoring of dialysis access. Int J Nephrol 2012:649735

10. Lazarides MK, Georgiadis GS, Argyriou C (2014) Aneurysm formation and infection in AV prosthesis. J Vasc Access 15(Suppl 7):S120-S124

11. Lockhart ME (2001) Robbin ML: hemodialysis access ultrasound. Ultrasound Q. 17:157-167

12. Malovrh M (2008) Nativearteriovenous fistula: preoperative evaluation. Am J Kidney Dis 39:1218-1225

13. Matsui S, Nakai K, Taniguchi T et al (2012) Systematic evaluation of vascular access by color-Doppler ultrasound decreased the incidence of emergent vascular access intervention intervention therapy and X-ray exposure time: a single-center observational study. Ther Apher Dial 16:169-172

14. Mudoni A, Cornacchiari M, Gallieni M, Guastoni C, McGrogan D, Logias F (2015) Aneurysms and pseudoaneurysms in dialysis access. Clin Kidney J 8: 363-367

15. Nalesso F, Garzotto F, Petrucci I, Samoni S, Virzì GM, Gregori D, Meola M, Ronco C (2018) Standardized protocol for hemodialysis vascular access assessment: the role of ultrasound and color Doppler. Blood Purif. 45:260-269

16. National Kidney Foundation. K/DOQI Clinical Practice Guidelines for Vascular Access: update 2000.Am J Kidney Dis. 2001;37(1):137-81.

17. Salman L, Beathard G (2013) Interventional nephrology: physical examination as a tool for surveillance for the hemodialysis arteriovenous access. Clin J Am Soc Nephrol 8:1220-1227

18. Shenoy S, Darcy M (2013) Ultrasound as a tool for preoperative planning, monitoring, and interventions in dialysis arteriovenous access. AJR 201: W539-W543

19. Soliman H, Raafat T, Abdelhamid YM (2015) Angiographic mapping of AV fistula related vascular complications in ESRD via multislice $C T$; adjuvant role in correlation with CDUS. EJRNM 46:665-674
20. Tirinescu DC, Bondor CJ, Vlăduțiu DŞ, Pațiu IM, Moldovan D, Orășan R, Kacsó IM (2016) Ultrasonographic diagnosis of stenosis of native arteriovenous fistulas in haemodialysis patients. Med Ultrason 18:332-338

21. Wiese P, Nonnast-Daniel B. Colour Doppler ultrasound in dialysis access. Nephrol Dial Transplant. 2004;19(8):1956-63.

22. Vascular access 2006 work group (2006) Clinical practice guidelines for vascular access. Am J Kidney Dis 48(Suppl 1):S176-S247

23. Zamboli P, Fiorini F, D'Amelio A, Fatuzzo P, Granata A (2014) Color Doppler ultrasound and arteriovenous fistulas for hemodialysis. J Ultrasound 17:253-263

24. Minion DJ, Moore E, Endean E (2005): Revision using distal inflow: A novel approach to dialysis-associated steal syndrome. Ann Vasc Surg; 19(5): 625-8.

\section{Publisher's Note}

Springer Nature remains neutral with regard to jurisdictional claims in published maps and institutional affiliations.

\section{Submit your manuscript to a SpringerOpen ${ }^{\circ}$ journal and benefit from:}

- Convenient online submission

- Rigorous peer review

- Open access: articles freely available online

High visibility within the field

- Retaining the copyright to your article

Submit your next manuscript at $\boldsymbol{\nabla}$ springeropen.com 